\title{
Fact from Opinion
}

\author{
PERRY WEDDLE California State University, Sacramento
}

For years a well known publication billed itself as "the newsmagazine that separates fact from opinion." Regardless of to what extent that publication spread the phrase "fact from opinion" into educated speech, there it is, a staple even more in education speech than in educated speech generally. In this meditation I try two things. First and much the longest I try to isolate strands of meaning masked by that phrase and its first cousins. Frequently I find not neat strands but instead illbraided or discontinuous bits masquerading as sound cordage. So my findings are not like a fisherman's backlash snarl, the kind which with patience may be unsnarled into usable line. They lead to the second thing I try-to give alternative expression to the educationally commendable goals which, by means of the attempted distinction, we wanted to achieve.

What does it mean to "distinguish fact from opinion?" Let me count the ways.

1. The Distinction as Semantic. Actually, fact and opinion could be separated easily. Whereas facts are states of affairs - what they are regardless of what anybody may think -opinions are human claims about states of affairs. It may be fact that fewer than five people in the room were born in Bulgaria, but it would not be an opinion until someone at least ventured it. Another way of stating the point would be this: If $\underline{x}$ be opinion then $\underline{x}$ is somebody's, that of a person or body of persons, whereas if $\underline{x}$ be fact then $\underline{x}$ is not somebody's. This would be a mathematician-like way of noting that for opinions the question, "Whose opinion is it?" is germane, and of noting that the question, "Whose fact is it?" except as joking, doesn't make sense. I will call this the "Whose?" test. That the "Whose?" test works yet trivializes the distinction ought to alert us. There's something suspicious about trying to counterbalance the one category against the other. That there might be a problem, however, seems to have been widely missed. Equally important, such an understanding of the difference would fail to convey what as educators we want to achieve. We want students to learn far more than how to spot semantic cues.

The "Whose?" test can be shortcircuited easily. By replacing "fact" in the distinction with something already somebody's, something such as "statements of facts," we could eliminate the grammatical cue. Indeed, several versions discussed below almost do this. The substitution, moreover, may move us close to what we had in mind for our classes, for didn't we want them to be able to spot slanted journalism, inadequate support, and the differences between description and prescription? Such matters are verbal, and very human. But if substituting the likes of "statements of fact" would constitute an advance, it would have corresponding drawbacks. We would no longer have a distinction between fact and opinion. 
We would have something considerably more modest. For there are more facts in heaven and earth than are contained in human statements. Untold facts await discovery. There are facts totally forgotten by humanity. There are unknown facts created along with the evolution or invention of conventions and systems. We want students not to confine themselves to the already stated. We would also like them to discover.

Now perhaps we meant all along that we wanted to teach the separation of statements of fact from opinion. But we should have said so. And when we did say so we should also have said that we were not teaching the separation of fact from opinion.

2. The Distinction as Fact vs. Falsehood. From the Greenhaven Press test, "Basic Skills for Critical Thinking," by Gary McCuen, consider this question.

Which of the following sentences is a statement of fact rather than of opinion?
A. There are no differences between the Democratic and the Republican parties.
B. Democrats and Republicans often disagree over the issue of welfare.
C. Republicans always vote for big business.
D. Democrats always vote for the common man.[1]

The keyed answer is $B$. Apparently the author felt that distractors $A, C$ and $D$ being false relegates them to the realm of opinion, whereas answer B being true relegates it to the realm of fact. This would be a misunderstanding, for opinion can be, indeed frequently is, correct. Just possibly the question's author felt that the answer being qualified or moderate, and the distractors the opposite, relegated them to their respective realms. Neither would this do, for many an undoubted statement of fact is unqualified-' "Oboes are mu- sical instruments," for examplewhereas qualified statements are frequently opinion, or false-for example, "In a right triangle the square of the hypotenuse may perhaps, at least sometimes, equal the sum of the squares of the adjacent sides." Now of course we very much want students good at seeing when they should be qualifying their claims, and at seeing when the claims of others need qualification-we want to turn out neither Archie Bunkers nor Casper Milquetoasts. But with the relationship between fact and opinion this has little directly to do.

With a fact-falsehood interpretation of our subject there would be further questions about educational value. Emphasis would be in the wrong place-as may be brought out by the following. Envision a dispute wherein either side has good but not complete evidence, and one side or the other must be right. (Say it's a round of dice, both cups having been overturned but with their contents yet to be revealed.) Would the outcome make the contentions of the one side fact, and those of the other side opinion? To affirm so would be extreme, for the dispute's about exactly the same thing, exactly the same matter of fact, and each side's got about as good a case. The difference would not be educationally important. The difference would be pure luck.

\section{The Distinction as Fact vs. Rea-} soned Judgment. Perhaps the question "Is that a fact or is that his opinion?", where "opinion" would be somebody's careful interpretation, conveys the difference we want. Something may be open to several interpretations, but that same something could not be said to be open to several facts. And interpretations may be closer to or further from fact, but the same would not be true for fact itself. Opinions differ, one might say, facts don't. 
Possibly the California State University Chancellor's Office intended something like this version of the distinction in the critical thinking paragraph of Executive Order 338-which mandates that undergraduates in the 300,000 student system be taught to distinguish 'between fact and judgment." The 338 language does reflect usage, as in the testimony (reported in the Sacramento Bee) of Cordon Wade, formerly in the management of Proctor and Camble:

\section{When I first arrived there, fresh from Harvard, I kept wanting to say, "In my judgment." I can still hear the response. "Your judgment's no better than the drunk in Lytle park." At Proctor, they pay you for removing judgment.}

But there's a problem. A distinction should distinguish, at least in the bulk of the cases it covers, and a fact/reasoned judgment version would not distinguish. Consider the record of my local weatherperson, Stormin' Norman. It is (1) Stormin' Norman's opinion that it'll be fair today and (2) a fact that it's fair today-Stormin' Norman knows his stuff. But to a great extent don't we all? This would mean that countless opinions would be facts, and that countless facts would be opinions. The imagined slash between fact and opinion would become an indefinite, leagues-broad swath.

\section{The Distinction as Fact vs. Mere} Conjecture. Like Stormin' Norman, most of us when plying our trades, or when cautious, are pretty good at making reasoned judgments. But what of our unguarded moments? What of unfamiliar terrain? What of the fools among us and the fool in each of us? If reasoned judgment turns out frequently to be fact, this scarcely means that mere conjecture does. Accordingly, to teach students to appreciate the difference between fact and mere conjecture may seem to be our goal, a goal moreover, well enshrined in usage - as in, "That's just your opinion" and in, "One opinion is as good as another." If opinion were mere conjecture, then such dismissals would not infrequently be well taken. And for sure we want students good at being able to see when somebody states fact and when somebody merely runs off at the mouth.

But that a fact-mere opinion contrast is the expression we want to give to these educationally desirable abilities, I doubt. Implicit in the factconjecture version of the contrast, as in others, is the assumption that fact is superior, that the better half of the distinction lies on the left. But does it? I once overheard a dispute over whether Ireland is west of Scotland. In the course of the discussion it became clear that neither party had the foggiest notion of a true map. Both parties were shooting off their mouths. One party just happened to have stated fact. It was by fool's luck. Educationally speaking, that party's no more admirable than the other.

Furthermore, if one ought not automatically to laud statements of fact, neither ought one automatically to downplay conjecture. In its place conjecture, even wild conjecture, can be admirable. We want students to be good at imagining, good at free-association, good at creating fusillades of hypotheses. Wild conjecture, one might even say, is the soul of scientific advance, or indeed of any advance. (Along with the creativity, of course, we want students to be good at seeing conjecture as conjecture, good at evaluating conjecture, and good at seeing the point of the free-wheeling. And that means seeing that whatever ultimately counts does so in direct proportion to the firmness of the grounding.)

5. The Distinction as Observation vs. Inference. The California Department of Education is now preparing to ad- 
minister a multiple-choice social studies test to the state's quartermillion-plus eighth graders. Eventually there will be analogous tests at the sixth, tenth, twelfth and third grades. That's well over a million kids. The commission which mandated the test expressed the desire that $40 \%$ of the items involve something called critical thinking. The rainbow committee of educators formed to construct the instrument decided, among many others, to test the ability to distinguish fact from opinion, which the committee defined as the difference "between observation and inference."

Although this comittee's construal may constitute an advance, I do wonder. Again the version fails to distinguish. Countless facts and opinions are best seen neither as simply observation nor inference. Last night on PBS Bill Moyers served up the standard explanation of the Depression-era migration to California from the South and Midwest. What Moyers said is fact, at least as far as 1 know, yet how rich a mixture its backing is. There are 60year olds recalling the motives they had 50 years back. There are diaries, bank records, textbook accounts of farming practices, tree-ring and census data, and the vivifications of Steinbecks and Dorothea Langes. There are professors renowned for their "sense of history." Whatever category one were to try helpfully cramming all such information into would be complex indeed, much more complex than either observation, inference or both.

There is, furthermore, the implication that observation, fact, belongs in the catbird seat. Frequently it's the other way 'round. An acquaintance of mine on a backpack trip, these are her words, "Saw a twelve-foot pterodactyl swooping down from Rodriguez Ridge." Having just ingested hallucinogenic mushrooms this person quite properly inferred that her observation was less than veridical. Com- pared to her observation her inference is in much the firmer epistemic position. Some inferences, moreover, are simply impeccable, such as a valid syllogism, or the correct solution to an algebraic equation.

There are further difficulties. Countless facts are not observations. Consider two examples. Fact One: Two plus two equals four. You couldn't observe that two plus two equals four. The equation is general, covering any case, including calculations done tomorrow. Furthermore, what you can observefor example a carefully-measure two ounces of bourbon plus a carefullymeasured two ounces of water-very often does not equal four. (Alcohol is somewhat soluble in water.) Fact Two: "Washington is in the northwest part of the country." This "fact" answer was submitted for the State of California test. The sentence would indeed state a paradigm fact. Yet only an astronaut could observe that Washington is in the northwest part of the country.

Of course, one can observe indirectly. This is what Lewis and Clark must have done-using the magnetic compass, the sun, the length of a day's march and so on to reckon, to deduce, that the wild land they were in lay northwest of from where they had commenced. Fact and observation, yes, but inference equally, the pair intertwined inextricably. And let's ask, I mean really, how do we know that Washington is in the northwest part of the country? Didn't we take somebody's word for it? That's how we know most of what we know, by appeal to authority. That's an honorable method-and if we don't think so then why are we teaching?-but observation it ain't.

\section{The Distinction as the Verifiable} vs. the Not Verifiable. Recently I saw a draft of a paper being prepared for teachers whose pupils will be taking that Department of Education social studies test, the one which by attempt- 
ing to measure the ability to distinguish observation from inference attempts to measure the ability to distinguish fact from opinion. In the draft, by Dr. Peter Kneedler, Consultant at the Department, "fact from opinion" and "observation from inference" are explained as follows. Facts are "statements of observations which can be proved true or verified." Opinions are "expressions of approval or disapproval." I'll call it the "draft", to remember that this is only a draft, and discuss it because it represents a respected view. It's close to the version in the Greenhaven Press test teacher manual, which defines statements of fact as "those which can be demonstrated empirically," and statements of opinion as "beliefs or attitudes which cannot be proved." Let's look at the "fact" haives of these definitions first; and because comments about statements and about observation have already been made, here I'II consider only the fact halves' "verifiability" parts. Afterwards I'll look at the "opinion" halves.

Are statements of fact verifiable? One might say so, but this would not separate them from opinions. Opinions are verifiable, too. For instance, in my opinion this paper can be delivered orally in fewer than 45 minutes, a fact, which supposing that 1 were right, would be easy to verify. And herein lies another problem: Suppose that I were wrong. Neither distinction seems to have left room for falsehood. Obviously falsehoods can't go on the "fact" side, but there seems to be no room for them on the "opinion" side either. Yet were not the critical-thinker abilities to smell and to detect falsehood one main force behind our wanting to teach the fact-opinion distinction? If so, then a viable version would have to include the possibility of falsehood.

One more point about the "verifiability" versions' "statements of fact" category: Why should it be confined to the empirical? Many a fact is based not on observations, not on the empirical, but on, for example, adding a column of numbers, or interpreting a passage, or tracing out the implications of a set of assumptions. Important critical-thinker abilities all, would not each belong in an educationally sound version of the distinction?

Now for the "opinion" halves of the two versions. Are opinions statements of either "beliefs or attitudes which cannot be proved" (that's Greenhaven) or "expressions of approval or disapproval" (that's the draft). And does defining them as such separate them in an educationally useful way from fact? Well, clearly some opinions are either, or both. Last month I was told, "The world would be a better place if you were to burn that necktie." Not only can the claim not be proved, since for one thing I refuse to burn the tie, the claim is clearly an expression of disapproval. But there are problems. Countless opinions not only can be proved but do get proved. Countless opinions, moreover, express neither approval nor disapproval. Recall Stormin' Norman's opinion about today's weather. Have we any idea how Stormin' Norman feels about today's weather? Nor would it matter how Stormin' Norman felt. Indeed in giving professional opinions reliable people usually want precisely to avoid expressing approval or disapproval. They are there to give objective interpretations, to state the facts as best they can, not to color matters one way or another. Even when we give plain opinions, not professional opinions, we may not approve or disapprove. Whether this paper would run under or over 45 minutes may or may not be of concern to me, but in any case you knew my opinion before you knew whether I approve, don't, or don't care.

A word had better be said about "expression of emotion," something into 
which the likes of "beliefs or attitudes" and "expressions of approval or disapproval" sometimes get unfolded. That understanding of "opinion" would not work either, for reasons just considered. Moreover, countless statements of fact also happen to be expressions of emotion. In only unusual circumstances could true accusations like "You molested my child!" be uttered without expressing emotion. The utterers, however, whatever the emotional accompaniments, would of course have been stating fact. Furthermore, countless opinions are delivered unemotionally. This goes no distance toward making them fact. They are or are not fact not because of emotional accompaniments but because of something else.

\section{The Distinction as Settled Matters}

vs. Controversial. The multiple-choice question which pegged the state-ofWashington sentence fact pegged as opinion the sentence, "Oregon is the most beautiful state in the union." Now there would be no controversy over the Washington claim but plenty over the Oregon claim. Is that the distinction then, settled vs. controversial? The suggestion has merit in that we would like students to appreciate when they need to supply argument for a point, namely when it's controversial or likely to be, and when they need not supply argument for a point-when there's general agreement. We don't want students begging questions or plumping at length for the obvious. The suggestion, furthermore, reminds that controversy or its likelihood is in many circumstances precisely what makes something a matter of opinion. And where there be unanimity this is indicator that the matter has been settled and relegated, accordingly, to the realm of fact.

But educational considerations and others cloud even this horizon. The suggested version would not well distinguish. Many a controversy is caused by fools, or stirred up by journalists. Furthermore, many an "established fact" has turned out to have been no more than complacency in the community of experts, or copycatting among journalists. A settled-vs.-controversial version of the fact-opinion distinction would place emphasis in the wrong place, place it, again, on an accompaniment of what counts, and not what really counts. This is partly due, no doubt, to "opinion" having semantic connection with controversy. But for students it won't do. If it were to do, then we should have to say that a dose of adrenaline or of Valium administered to one side or another over an issue would change fact to opinion, or vice versa. That would not be education but chemistry. We don't want students counting heads in order to make policy. Instead, we want them asking, "Regardless of what proportion support it, what are their reasons; what are the facts?"'

8. The Distinction as Reporting vs. Advocating. Although I failed to find this version in any obvious source, surely it is quite unoriginal. It's what is assumed to distinguish the main news pages of a newspaper from the editorial pages. In other words, the newsmagazine with the slogan would have been far from original either. But again I wonder.

Consider the lead story in the June 18, 1984 Sacramento Bee under the headline, "foreign trade deficit record $\$ 19.4$ billion." Assuming the headlineand-story accurate, would that make it fact? I would say yes. It taps no questionable sources, succumbs to no obvious sophistry. The statistic could appear in next year's edition of Facts on File. But would any such considerations mean that opinion is not also heavily admixed? Wherever the -story were rationally placed in the newspaper, somebody would have had to decide that the story, with that size headline, 
ought to go there, that in that person's opinion that news is prime. The placement expresses a viewpoint. Another viewpoint would have emphasized the story less, big trade deficits being a quite foreseen, and therefore unsurprising, and therefore less newsworthy, negative consequence of overall Reagan Administration policy: The Bee story is what of a Democrat paper reporting to its chiefly Democrat readers, Fact, yes, but opinion too. As in many contexts the pair intertwine. And as educators, we would like our clients to understand all sorts of such intertwining, as in the present case, not merely to separate the pure one (supposing that it could be done), from the pure other.

And what about the "advocacy," the "opinion" side of this version? Along toward November the big trade deficit became an editorial salvo hurled against the Administration. Did that make it opinion or closer to opinion? Why say so; it's the same fact?

Now perhaps everyone knows that opinions worth considering are backed by facts. What, however, of editorial bottom lines, the "ought" conclusions borne of facts? Are they then opinion? That will depend. They may be opinion, but not simply because they're advocacy, not simply because they are "oughts." Starting to build a board fence around my lot, after the first day I heeded my neighbor's advice. "You know," he said, "if you want to knock that thing together efficiently you really ought to get yourself a heavier, professional quality waffle-faced hammer." I did. I proceeded in accordance with my neighbor's opinion. The guy was dead right, and that's a fact.

Now my neighbor's "ought" differs only in degree, and in some cases not even in that, from "oughts" in good newspaper editorials and similar persuadings. The differences in degree are because the cases are worth arguing, because there are alternative opinions; and this makes the journalistic "oughts" opinion. But they may be fact, too. Is a light-rail public transport system for Greater Sacramento financially wise? The Bee editorializes so. Looking back from 1994 to 1984 , we will be able to see-just as I was able to see about that wafflefaced hammer. The Bee, or its opponents, will have stated fact.

Upshot. Undoubtedly there exist further ways plausibly to construe a contrast between fact and opinion. And although one which does the job perfectly may surface at any time, for two reasons I doubt that one will. First, "fact" and "opinion" each has multiple shades of meaning. This makes essence-hunting difficult if not impossible and exception-finding easy and rich. Think of the differences just between "mere opinion," "professional opinion," "received opinion," "dissenting opinion," "second opinion," and "difference of opinion." It would take a John Austin to sort them out, and such a list would be but a beginning. The same would hold for "fact," a miasma which only an epistemologist could love. Second, unlike genuine opposites - such as on-off, hot-cold, malefemale - this one draws its constituents from mutually compatible, but different types, of category. (It could be called a "category mistake.") Claiming to be able in general to ask, "Is that fact or is it opinion?" is like claiming to be able in general to ask of a politician, "Is she a Republican, or is she a ... conservative?" Where we would have expected "Democrat," or something of the same order, we get something of a different order. And so we shouldn't be surprised if the answer turns out to be, "Both." Or, "Neither." Or, "Whaddya mean?"

In our urge, however, to want students to be good at separating fact from opirion, there was something undeniably right. We see them falling for 
or rejecting teachers, diets, studentbody presidential candidates, music, career choices - all on flimsy ground or what masquerades as grounds. We see them swayed by question-begging slogans like "Abortion is baby-killing" and "Abortion is free choice" - as if either stated uncontroversial, established fact. But we also see glints of real intelligence often enough to sense that teachable subject really does lurk out there: "If only they could see the facts," we think, "and ignore that cacophonous gaggle of opinion." Here the contrast makes itself felt. But if my ruminations be close to the mark, the pull is folklore, and if so we suffer from what I once heard described as "hardening of the categories."

We need something better, but what? I fancy the answer to be not all that tough. At bottom it's a matter of evidence quality: The existence of complete evidence renders a contention fact or false, though it may also be opinion; the existence of partial or no evidence renders a contention opinion, though it may also be fact. For this reason the distinction doesn't matter, while evidence quality matters very much.

And isn't this what we wanted all along? We wanted students good at demanding and assessing support for what's laid on them, and good at mustering strong support for what they lay on others. We wanted them to ask, "How is that known,?" and to be able and disposed to employ all sorts of devices with which to calibrate likeli- hood that the contention at issue is correct or false. I am pleased to see many such devices in the several documents cited-guidelines for gauging reliability of sources, for example, for generalizing responsibly, for measuring relevance, and for recognizing common foibles. So if I have been polemical here, it's against neither whole nor parts but only against one part which in my opinion (if I may be allowed the term) deserves tougherminded scrutiny than it has been receiving. Literally millions are being spent on it, and that's a fact. [2]

\section{NOTES}

[1] Gary McCuen, "Basic Skills for Critical Thinking," St. Paul, Minn., Greenhaven Press, copywright 1979 , with "Teachers Manual." The question is from Test Form 1.

[2] This is a revised version of a paper delivered to a group of educators at the Second International Conference on Critical Thinking and Educational Reform at Sonoma State University, Rohnert Park, California, July 9-13, 1985.

Perry Weddle is a Professor of Philosophy and the founding Director of the Critical Thinking Project at California State University, Sacramento.

Perry Weddle, 2511 Q Street, Sacramento, CA 95816 